\title{
Role of sublingual nitroglycerin in patients with acute myocardial infarction ${ }^{1}$
}

\author{
Cesar E. Delgado, ${ }^{2}$ Bertram Pitt, Dean R. Taylor, Myron L. Weisfeldt, and David T. Kelly \\ From the Department of Medicine, Fohns Hopkins University and fohns Hopkins Hospital, Baltimore, \\ Maryland, U.S.A.
}

\begin{abstract}
Fourteen patients with acute myocardial infarction were given $0.3 \mathrm{mg}$ sublingual nitroglycerin within the first I2 hours of their acute myocardial infarction. Five minutes after sublingual nitroglycerin mean arterial pressure fell $9 \mathrm{mmHg}(\mathrm{I} .2 \mathrm{kPa})$ and remained significantly reduced for 30 minutes. Pulmonary capillary wedge pressure fell from a mean control value of $I 7$ to $I 2 \mathrm{mmHg}(2.3$ to $I .6 \mathrm{kPa})$ and also remained reduced for 30 minutes. Heart rate was significantly raised and stroke work index reduced at five minutes. Patients with a stroke work index of greater than $55 \mathrm{~g} \mathrm{~m}$ per $\mathrm{m}^{2}$ b.s.a. responded to nitroglycerin with a fall in both pulmonary capillary wedge pressure and stroke work index while in those with a stroke work index of less than $55 \mathrm{~g} \mathrm{~m}$ per $\mathrm{m}^{2}$ b.s.a. stroke work index did not fall concomitantly with the fall in pulmonary capillary wedge pressure. In one patient, nitroglycerin led to a precipitous fall in arterial pressure and recurrence of chest pain.
\end{abstract}

Nitroglycerin has been considered to be contraindicated in acute myocardial infarction because it may lower systemic blood pressure and cause a reflex rise in heart rate (Friedberg, 1966). Recent work has, however, suggested that vasodilator drugs may be useful in the therapy of myocardial infarction, as pump performance may be improved while at the same time myocardial oxygen demand is decreased (Franciosa et al., 1972; Kelly et al., 1973). These studies have renewed interest in nitroglycerin therapy in acute myocardial infarction. In experimental animals with acute myocardial infarction, intravenous nitroglycerin has been shown to decrease the area of ischaemia as assessed by ST segment mapping (Smith et al., 1973). Gold, Leinbach, and Sanders ( 1972 ) have given sublingual nitroglycerin to patients within a week after myocardial infarction and found that left ventricular function improved in patients with congestive failure but remained unchanged in those without significant heart failure. The purpose of this report is to examine the haemodynamic response to sublingual nitroglycerin during the early hours after myocardial infarction and to assess its role in the early therapy of patients with acute myocardial infarction.

Received 16 August 1974.

${ }^{1}$ Supported by the Myocardial Infarction Research Unit Contract with the National Institutes of Health and Department of Health, Education and Welfare.

${ }^{2}$ Fellow of American Heart Association.

\section{Subjects}

Fourteen patients with acute myocardial infarction were studied at an average time of 8 hours (range 4 to I4 hours) after the onset of symptoms. The average age of the patients was 57.9 years, 8 were men and 6 were women; Io white and 4 black. Two patients had subendocardial myocardial infarction and 12 transmural infarction of which 8 were inferior and 6 anterior. All patients had raised serum creatine phosphokinase enzymes. Two patients had had a previous myocardial infarction; 2 had chronic angina pectoris; 5 had a history of hypertension, but none was receiving treatment for it, and one patient had chronic congestive heart failure. The I4 patients were clinically classified according to the Killip Classification (Killip, 1968); 7 patients were in Class I, with uncomplicated myocardial infarction; and 7 in Class II, with clinical or radiological signs of early left ventricular failure. All patients had received oxygen, narcotics when indicated for pain, and lignocaine for ventricular arrhythmias when indicated, but no inotropic drugs or diuretics were administered before nitroglycerin. The procedure was explained to the patients and informed consent obtained.

\section{Methods}

A Swan-Ganz catheter was inserted in a right antecubital vein for right heart catheterization; arterial pressures were measured by an indwelling radial artery needle inserted percutaneously. The pressures were measured with a Statham transducer using the midchest position as the zero reference point and recorded together with the electrocardiogram on a four-channel 
direct writing recorder (Brush Mark II-40). Mean pulmonary capillary wedge pressure was taken to represent left ventricular filling pressure. Cardiac output was measured by the thermodilution technique (Forrester et al., 1972) using a Swan-Ganz thermodilution catheter (Edwards Laboratories, Model No. 93-113-7F) and $5 \mathrm{ml}$ room-temperature injectate introduced into the right atrium. The accuracy of this system had been previously compared with direct Fick measurements; the average of two thermodilution cardiac outputs had a standard error of \pm 4 per cent of the cardiac output as determined by the Fick method (Korner et al., 1973). In this laboratory the average of two thermodilution cardiac outputs was compared simultaneously with two indocyanine green dye curves in a group of to patients after acute myocardial infarction; the linear regression did not differ significantly from the line of identity and the correlation was 0.93 .

The figures for cardiac output in the study represent the mean of two sequential determinations in 73 of the 83 outputs determined. The remaining Io were calculated from one injection of saline. The linear regression of the plot of the two determinations had a slope of 0.95 and did not differ significantly from the line of identity. The correlation was 0.93 .

Control measurements of pulmonary artery wedge pressure, arterial pressure, and cardiac output were made and repeated after 20 minutes. Since there were no significant differences during the control period for any of the variables measured (Fig. I) the mean of the two control figures was used as the control value for subsequent statistical analysis.

Nitroglycerin $0.3 \mathrm{mg}$ was given sublingually and pressure and output determinations were made 5, I0, 15, and 30 minutes after nitroglycerin.

The derived haemodynamic variables were calculated as follows:

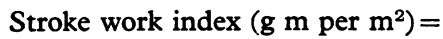

$$
\frac{\text { SVI }(\text { MSP }- \text { PCW }) \times 1.36 \times 1.005}{100}
$$

SVI $=$ Stroke volume index $\mathrm{ml} / \mathrm{m}^{2}$

MSP $=$ Mean systolic arterial pressure $\mathrm{mmHg}$

$\mathrm{PCW}=$ Pulmonary capillary wedge pressure $\mathrm{mmHg}$

Systemic vascular resistance (units) $=\frac{\text { MAP }- \text { RAP }}{\text { CO }}$

$\mathrm{MAP}=$ Mean arterial pressure $\mathrm{mmHg}$

$\mathrm{RAP}=$ Right atrial pressure $\mathrm{mmHg}$

$\mathrm{CO}=$ Cardiac output litres/minute

The results were analysed by Student's paired $t$ test.

\section{Results}

The mean values for the measured and derived haemodynamic variables in the 14 patients with acute myocardial infarction before and after $0.3 \mathrm{mg}$ of sublingual nitroglycerin are shown in Fig. I. There were no significant differences in any of the parameters between the first and second control observations. Five minutes after sublingual nitro-
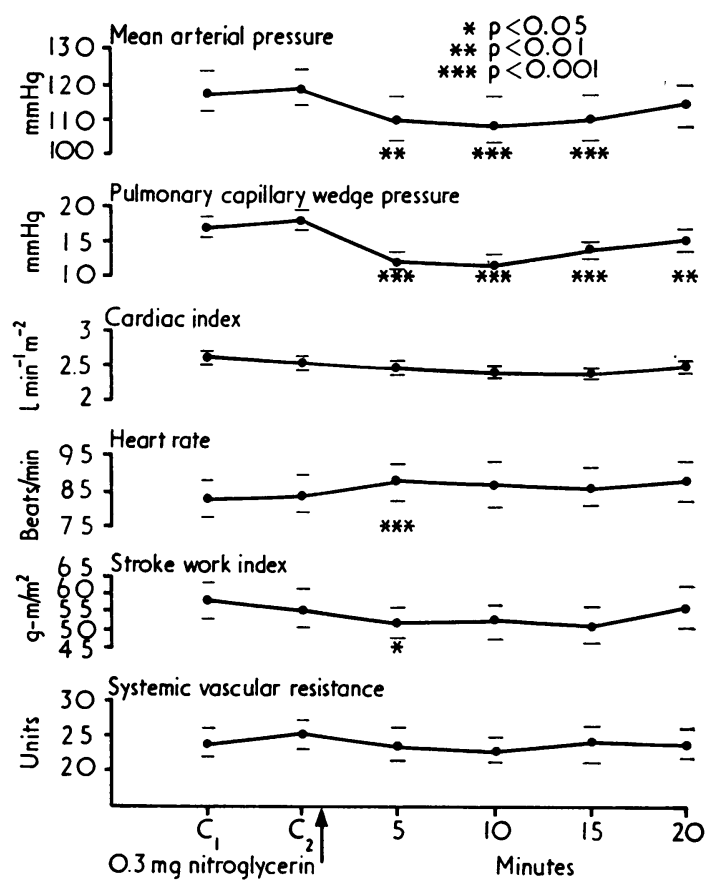

FIG. I Haemodynamic effects of $0.3 \mathrm{mg}$ sublingual nitroglycerin in 14 patients with acute myocardial infarction. The mean values and standard errors are shown during two control observations $C_{1}$ and $C_{2}$ separated by 20 minutes, and after nitroglycerin.

glycerin mean arterial pressure fell significantly to I Io mmHg (I $4.6 \mathrm{kPa}$ ) from a mean control value of $119 \mathrm{mmHg}$ (I5.8 kPa) and remained significantly reduced for 30 minutes. Pulmonary capillary wedge pressure (left ventricular filling pressure) fell significantly to $12 \mathrm{mmHg}$ ( $1.6 \mathrm{kPa}$ ) from a control value of $17 \mathrm{mmHg}(2.3 \mathrm{kPa})$ and also remained significantly reduced for the 30-minute period of observation. Cardiac index did not significantly change after administration of sublingual nitroglycerin. Heart rate was slightly raised for the 30 minutes of observation after sublingual nitroglycerin, but this increase was significant only after 5 minutes. Similarly, stroke work index was significantly reduced to $52 \mathrm{~g} \mathrm{~m}$ per $\mathrm{m}^{2}$ from a control value of $57 \mathrm{~g} \mathrm{~m}$ per $\mathrm{m}^{2}$ only at five minutes after administration of sublingual nitroglycerin. Systemic vascular resistance did not significantly change following administration of nitroglycerin.

In one patient (Fig. 2) sublingual nitroglycerin led to a precipitous fall in mean arterial pressure and a recurrence of a praecordial chest pain. The hypotension and chest pain responded to raising the 

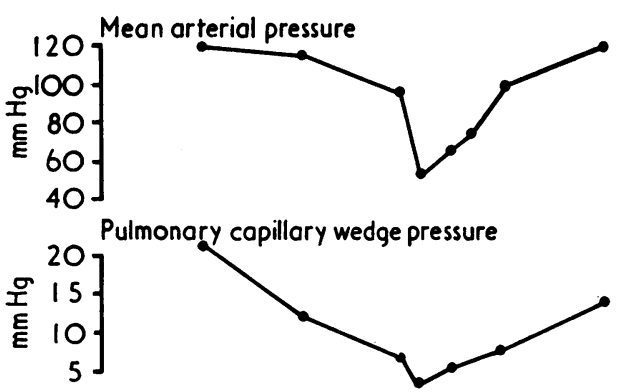

مE

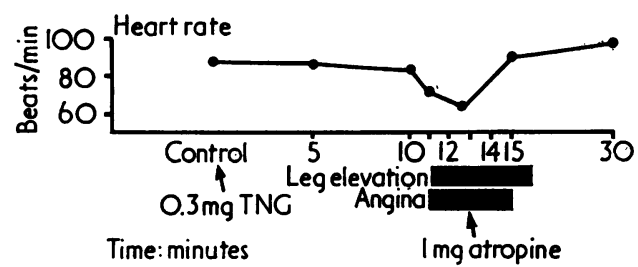

FIG. 2 Haemodynamic effects of $0.3 \mathrm{mg}$ sublingual nitroglycerin in a patient who developed a precipitous fall in mean arterial pressure. Note the recurrence of chest pain associated with the hypotension. The patient's symptoms and hypotension were relieved by raising the legs and $I \mathrm{mg}$ atropine.

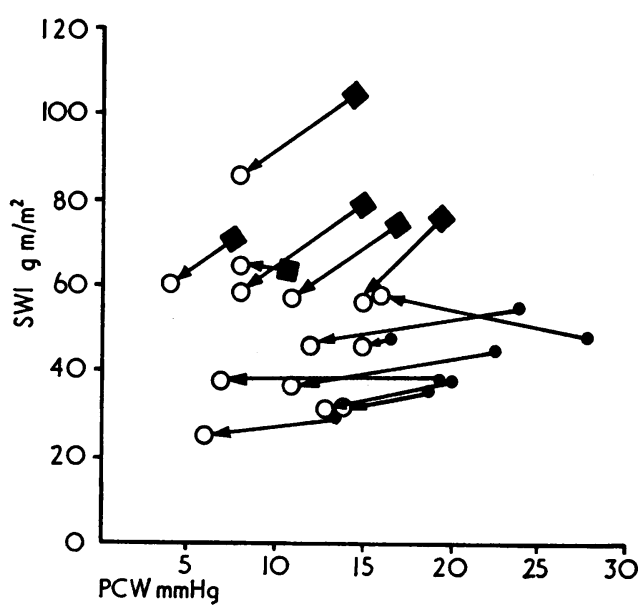

FIG. 3 Relation between stroke work index (SWI) and pulmonary capillary wedge pressure (PCW). The solid squares are the control observations in patients with a SWI of greater than $55 \mathrm{~g} m$ per $m^{2}$ b.s.a. $\left(\mathrm{g} \mathrm{m} / \mathrm{m}^{2}\right.$ ) (group $\mathrm{I}$ ) and the solid circles those with a SWI of less than $55 \mathrm{~g} \mathrm{~m}$ per $\mathrm{m}^{2}$ b.s.a. $\left(\mathrm{g} \mathrm{m} / \mathrm{m}^{2}\right)$. The open circles are the results at the peak effect of nitroglycerin on $P C W$. patient's legs and administration of $\mathrm{I} \mathrm{mg}$ atropine intravenously. The fall in mean arterial pressure occurred between the eleventh and fifteenth minute after administration of sublingual nitroglycerin and is, therefore, not reflected in the mean values for the entire group shown in Fig. I, recorded 5, 10, 15, and 30 minutes after administration of sublingual nitroglycerin.

The relation of stroke work index to pulmonary capillary wedge pressure is shown in Fig. 3 at the peak effect of sublingual nitroglycerin on pulmonary capillary wedge pressure. On the basis of this relation, the patients were arbitrarily divided into two subgroups. There were 6 patients with a stroke work index of greater than $55 \mathrm{~g} \mathrm{~m}$ per $\mathrm{m}^{2}$ b.s.a. (group I) and 8 patients with a stroke work index of less than $55 \mathrm{~g} \mathrm{~m}$ per $\mathrm{m}^{2}$ b.s.a. (group 2). The mean haemodynamic changes in group $I$ and group 2 patients after administration of sublingual nitroglycerin are shown in the Table. There were no significant differences between the control heart rates and mean arterial pressure in groups $I$ and 2 patients. There were, however, significant differences in pulmonary capillary wedge pressure, and cardiac index between group $I$ and group 2 patients. While mean pulmonary capillary wedge pressure in group I patients was $14 \mathrm{mmHg}(1.9 \mathrm{kPa})$, it should be noted that 4 of the 6 patients in this group had a pulmonary capillary wedge pressure of $15 \mathrm{mmHg}(2.0 \mathrm{kPa})$ or greater. Sublingual nitroglycerin decreased pulmonary capillary wedge pressure in both groups $I$ and 2 patients whereas stroke work index fell significantly only in group I patients.

\section{Discussion}

Sublingual nitroglycerin resulted in a significant fall in pulmonary capillary wedge pressure in 14 patients studied within I2 hours of onset of symptoms of myocardial infarction in the present study. There were, however, significant differences in the response in those patients with a stroke work index greater than (group I) and less than (group 2) 55 $\mathrm{g} \mathrm{m}$ per $\mathrm{m}^{2}$ b.s.a.

In group I patients nitroglycerin resulted in a significant fall in both pulmonary capillary wedge pressure and stroke work index. This response is similar to that seen with a diuretic (Kiely et al., 1973) and is caused by a reduction in venous return caused by peripheral venous pooling (Mason and Braunwald, 1965). Since the pulmonary congestion in group I patients is probably at least in part caused by a reduction in left ventricular compliance (Diamond and Forrester, 1972), it is not surprising that small changes in venous return, either by nitroglycerin or a diuretic, cause a significant fall in pulmonary capillary wedge pressure. Since the 
TABLE Haemodynamic changes in groups $I$ and 2 patients. The mean values and standard errors are shown

\begin{tabular}{|c|c|c|c|c|c|c|}
\hline & Control & $\begin{array}{l}\text { Mean arterial } \\
\text { pressure } \\
(m m H g) \\
I 23 \pm 5.3\end{array}$ & $\begin{array}{l}\text { Pulmonary } \\
\text { capillary wedge } \\
(\mathrm{mmHg}) \\
14 \pm I .8\end{array}$ & $\begin{array}{l}\text { Cardiac } \\
\text { index } \\
\left(\text { l min }^{-1} \text { per } m^{2}\right) \\
3.35 \pm 0.3\end{array}$ & $\begin{array}{l}\text { Heart } \\
\text { rate } \\
\text { (beats/min) } \\
81.3 \pm 6.3\end{array}$ & $\begin{array}{l}\text { Stroke work } \\
\text { index } \\
\left(g \mathrm{~m} \text { per } \mathrm{m}^{2}\right) \\
77.4 \pm 5.6\end{array}$ \\
\hline \multirow{2}{*}{$\begin{array}{l}\text { Group I } \\
6 \text { patients } \\
\text { SWI > } 55 \\
\mathrm{~g} \mathrm{~m} \text { per } \mathrm{m}^{2}\end{array}$} & TNG & II $5.3 \pm 8.3$ & $9 \pm 1.5$ & $3.0 \pm 0.4$ & $85 \pm 6.6$ & $6.35 \pm 4.5$ \\
\hline & $\begin{array}{l}\mathbf{P} \\
\text { Control }\end{array}$ & $\begin{array}{l}<0.05 \\
115.6 \pm 8.2\end{array}$ & $\begin{array}{l}<0.005 \\
20.4 \pm 1.6\end{array}$ & $\begin{array}{l}<0.02 \\
2.37 \pm 0.2\end{array}$ & $\begin{array}{l}\text { NS } \\
86.2 \pm 6.6\end{array}$ & $\begin{array}{l}<0.01 \\
4.19 \pm 2.9\end{array}$ \\
\hline \multirow{3}{*}{$\begin{array}{l}\text { Group } 2 \\
8 \text { patients } \\
\text { SWI < } 55 \\
\mathrm{~g} \mathrm{~m} \text { per m } \mathrm{m}^{2}\end{array}$} & TNG & IOI. \pm 8.7 & II.7 \pm 1.3 & $2.36 \pm 0.2$ & $88.3 \pm 6.9$ & $3.92 \pm 3.5$ \\
\hline & $\begin{array}{l}\text { P } \\
\text { Control group I }\end{array}$ & $<0.01$ & $<0.001$ & NS & NS & NS \\
\hline & $\begin{array}{c}\text { vs } \\
\text { Control group } 2\end{array}$ & NS & $<0.02$ & $<0.01$ & NS & NS \\
\hline
\end{tabular}

Conversion: Traditional Units to SI-Pressure: I $\mathrm{mmHg} \approx 0.133 \mathrm{kPa}$; Work: $\mathrm{I} \mathrm{g} \mathrm{m} \approx 10 \mathrm{mNm}$.

TNG: shows the measured and derived haemodynamics at peak nitroglycerin effect on the pulmonary capillary wedge pressure. $P$ : value obtained by Student's paired $t$ test of control versus TNG in each group. Control group I versus group 2: unpaired $t$ test $P$ values. NS: not significant.

majority of patients with a normal stroke work index can be expected to have a spontaneous diuresis (Hodges et al., 1970) the value of any therapy to reduce pulmonary capillary wedge pressure must be questioned.

Patients in group 2 also reponded to nitroglycerin with a significant decrease in pulmonary capillary wedge pressure, but in contrast to group I patients maintained their stroke work index. This response is similar to that found by Gold et al. (1972) also using sublingual nitroglycerin, Franciosa et al. (1972) using nitroprusside, and Kelly et al. (1973) using phentolamine, in patients with moderate left ventricular failure. The maintenance of stroke work index with a reduction in pulmonary capillary wedge pressure by sublingual nitroglycerin suggests that this agent might be useful in patients with severe left ventricular failure complicating infarction. The relative value of sublingual nitroglycerin as opposed to a diuretic, such as frusemide, has not, however, been demonstrated in patients with severe left ventricular failure either in the present or previous studies.

In addition to its possible haemodynamic benefits, nitroglycerin has also been shown to reduce myocardial oxygen requirements and infarct size in experimental animals (Smith et al., 1973). While it is possible that the area of myocardial ischaemia may have decreased after the administration of sublingual nitroglycerin because of a direct effect upon the coronary circulation, as suggested in animals after intravenous nitroglycerin (Smith et al., 1973), this effect may only be transient, as the haemodynamic effects of sublingual nitroglycerin last less than 30 minutes. To affect infarct size significantly, a longer effect would be desirable, such as obtained with intravenous nitroglycerin. In contrast to the possible beneficial effects, there is also a potential risk that the area of ischaemia could actually be increased after sublingual nitroglycerin. This was suggested by one of our patients in group 2 with pulmonary congestion (Fig. 2) who had an abrupt decrease in systemic pressure after sublingual nitroglycerin in association with the recurrence of praecordial chest pain. The level of diastolic pressure has been shown to be a major determinant of coronary perfusion. In patients with acute myocardial infarction where a tenuous balance already exists between myocardial oxygen supply and demands, any large decrease in coronary perfusion pressure may result in further ischaemia and infarct extension. We would, therefore, recommend that diuretics such as frusemide continue to be used as the primary therapeutic agent in patients with mild to moderate pulmonary congestion complicating their infarction and that sublingual nitroglycerin be reserved for those patients who fail to improve after a diuretic (Kiely et al., 1973). The use of intravenous nitroglycerin with concomitant arterial pressure monitoring and regulation may, however, prove to be useful if it can be shown that the beneficial effects on infarct size and fibrillatory threshold, demonstrated to occur in animals (Smith et al., 1973), can be duplicated in man.

\section{References}

Diamond, G., and Forrester, J. S. (1972). Effect of coronary artery disease and acute myocardial infarction on left ventricular compliance in man. Circulation, 45, 11 . 
Forrester, J. S., Ganz, W., Diamond, G., McHugh, T., Chonette, D. W., and Swan, H. J. C. (1972). Thermodilution cardiac output determination with a single flowdirected catheter. American Heart fournal, 83, 306.

Franciosa, J. A., Guiha, N. H., Limas, C. J., Rodriguera, E., and Cohn, J. N. (1972). Improved left ventricular function during nitroprusside infusion in acute myocardial infarction. Lancet, $\mathrm{r}, 650$.

Friedberg, C. K. (1966). Acute coronary occlusion and myocardial infarction. In Diseases of the Heart, 3 rd ed., p. 913. Saunders, Philadelphia.

Gold, H. K., Leinbach, R. C., and Sanders, C. A. (1972). Use of sublingual nitroglycerin in congestive failure following acute myocardial infarction. Circulation, 46, 839.

Hodges, M., Marx, H. J., Schreiner, B. F., and Yu, P. N. (1970). Clinically uncomplicated acute myocardial infarction: serial hemodynamic studies (abstract). American Fournal of Cardiology, 26, 638.

Kelly, D. T., Delgado, C. E., Taylor, D. R., Pitt, B., and Ross, R. S. (1973). The use of phentolamine in acute myocardial infarction associated with hypertension and left ventricular failure. Circulation, 47, 729.

Kiely, J., Kelly, D. T., Taylor, D. R., and Pitt, B. (1973). The role of furosemide in the treatment of left ventricular dysfunction associated with acute myocardial infarction. Circulation, 45, 581.

Killip, T. (1968). Coronary care units. In Acute Myocardial Infarction, p. 23. Ed. by D. G. Julian and M. F. Oliver. Williams and Wilkins, Baltimore; Livingstone, London and Edinburgh.

Korner, P. L., Shaw, J., Uther, J. B., West, M. J., McRitchie, R. J., and Richards, J. G. (1973). Autonomic and nonautonomic circulatory components in essential hypertension in man. Circulation, 48, 107.

Mason, D. T., and Braunwald, E. (1965). The effects of nitroglycerin and amyl nitrite on arteriolar and venous tone in the human forearm. Circulation, 32, 755.

Smith, E. R., Redwood, D. R., McCarron, W. E., and Epstein, S. E. (1973). Coronary artery occlusion in the conscious dog. Effects of alterations in arterial pressure produced by nitroglycerin, hemorrhage, and alphaadrenergic agonists on the degree of myocardial ischemia. Circulation, 47, $5 \mathrm{I}$.

Requests for reprints to Dr. Bertram Pitt, Johns Hopkins Hospital, 6or North Broadway, Baltimore, Maryland 21205 , U.S.A. 